\title{
El teatro de los muertos: teatro perdido, duelo, memoria en las prácticas y la teoría del teatro argentino
}

\author{
Jorge Dubatti ${ }^{1}$
}

Resumen:

El concepto del teatro de los muertos fue ganando en extensión y pasó a tener para nosotros también un sentido genérico: designa, en particular, el dispositivo poético de la memoria advertido en el teatro de la Postdictadura respecto de las experiencias y representaciones del pasado; en general, la inabarcable masa de teatro de quienes nos precedieron, el teatro que hicieron los ya muertos -artistas, técnicos, espectadoresy que, de alguna manera misteriosa, regresa cada vez que se produce un acontecimiento teatral. La memoria del teatro de los muertos se hace presente en cada nuevo acontecimiento. Por todo el teatro que hemos hecho y hemos visto, ya estamos nosotros también, los que aún vivimos, en el espesor histórico del teatro de los muertos.

Plavras-chave: Teatro de los Muertos, Duelo, Memoria del Teatro Argentino

\begin{abstract}
:
The concept of the theater of the dead has been growing in extension and acquired a generic sense for us: it refers particularly to the poetic device of memory noted in the post-dictatorship theater, related to the experiences and representations of the past; in general, the boundless mass of theater from our predecessors, theater made by the already dead - artists, technicians and spectators - which returns, in some mysterious way, every time a theatrical event occurs. The memory of the theater of the dead is present in each new event. For all the theater we've done and seen, we are - even being still alive - in the historic thickness of the theater of the dead.
\end{abstract}

Key-words: Theater of the Dead, Bereavement, Memory of the Argentinian Theater 
La literatura griega antigua que conocemos en la actualidad es un porcentaje mínimo de lo que se escribió: quizá poco más de un 10 por 100. A pesar de esta cifra tan decepcionante son más de dos mil los autores de los que conservamos restos.

Javier López Facal (2006, p. 285)

No podemos aspirar a reconstruir la forma original de un mito. Sobre todo cuando nos han llegado sus ecos fragmentarios de diversas épocas. Porque incluso las menciones más antiguas no dejan de ser fragmentos o variantes de un relato original parcialmente conservado y en parte perdido (...) los testimonios literarios que hemos conservado son una pequeña parte de la caudalosa narrativa mítica antigua, por tanto, hubo muchos relatos perdidos.

Carlos García Gual (2012, p. 73-74)

para que después visitemos a los muertos en

las catástrofes de los sueños.

Arturo Carrera, Noche y día (2005, p. 17)

Los espiritus de los hombres honrados nos envían un mensaje.

Thomas Ostermeier, director de Hamlet (en Dubatti, 2013b)

¿Voy a poder reemplazar a ese objeto? ¿No se relaciona precisamente mi duelo con él en cuanto irreemplazable?

Jean Allouch (2006, p. 49)

Estamos condenados a volver a enterrar a los mismos muertos. Parece que se van, pero se quedan. Como el disco de nuestro teléfono enlutado, apenas se desplazan un poco, para volver siempre al punto de partida.

Mónica López Ocón, “Teléfono” (2014: 8)

\section{Dispositivos de estimulación y actividad de la memoria}

Inicialmente, en nuestros estudios sobre el teatro de Postdictadura (DUBATTI 2003, 2005, 2007b, 2008a, 2011a, 2011b, 2013a, entre otros), al tratar el problema de los desaparecidos y las consecuencias de la dictadura 1976-1983 en la democracia a partir de 1983 hasta el presente, propusimos el concepto de "el teatro de los muertos" para definir una tendencia muy extendida de la escena argentina: el teatro crea dispositivos, de diversa morfología, que operan como estimuladores de la evocación de quienes ya no están entre nosotros. En este sentido, siguiendo a Hugo Vezzetti (2002), hemos señalado que el teatro de Postdictadura opera como un constructo memorialista (Dubatti 2006a, entre otros trabajos). Esos dispositivos de estimulación (más que de comunicación) ${ }^{1}$ hacen que los muertos se presentifiquen en la memoria del espectador aunque no se esté hablando explícitamente de ellos. Cada espectador, cada público proyecta a partir de esa estimulación (que opera por construcción de ausencia o de vacío a ser llenado, como es el caso del personaje de Godot en la pieza beckettiana) aquello que lo involucra, lo compromete, lo desvela. Cada espectador, cada público, proyecta sobre esa ausencia sus propias preocupaciones, deseos, construcciones subjetivas. En la Argentina los muertos habitan la conciencia de los espectadores de la Postdictadura, y el teatro y otras formas artísticas se encargan de invocarlos. En el teatro argentino basta con dibujar una silueta para que ésta invoque, recuerde, presentifique, llame, estremezca con las resonancias del

1 Véase al respecto el texto de nuestra conferencia "Teatro, comunicación, estimulación, afectación: reflexiones sobre la "zona" teatral" (2013c). 
pasado que regresa en cada espectador de manera diversa. En el teatro de Postdictadura que hemos visto en los últimos 30 años, hemos podido reconocer este procedimiento en piezas de Javier Daulte, Rafael Spregelburd, Ricardo Bartís, Eduardo Pavlovsky, Gonzalo Demaría, Mario Cura, Rodolfo Braceli, Marcelo Bertuccio y muchísimos otros.

Veamos brevemente tres ejemplos de rasgos diferentes. Un caso revelador - que hemos estudiado en esta dirección (DUBATTI, 2005, p. 179-198) - es el de ¿Estás ahí? (Teatro Nacional Cervantes, 2003) de Javier Daulte. La pieza tiene una deriva poética inesperada: comienza como una "sitcom" (comedia de situaciones) con el hombre invisible, de acuerdo a convenciones que provienen de los géneros codificados de la televisión o el cine americanos; de pronto se transforma en una comedia de muertos; vuelve a transformase, otra vez, ahora en una historia de amor imposible contada desde el punto de vista de una muerta. En esa deriva el personaje de Martín va mutando su carga referencial: del hombre invisible pasa a ser un fantasma, es decir, un muerto. Como todo fantasma, un muerto con un deseo o cuenta pendientes. En la Escuela de Espectadores fue inevitable, obvia la referencia a los desaparecidos y otras muertes nacionales. Sin embargo, la misma historia, en la versión catalana dirigida por Daulte, fue leída por el público y la crítica desde otra significación: el personaje del hombre invisible fue relacionado con el lugar de Cataluña en la Unión Europea.

En la pieza de Gonzalo Demaría El cordero de ojos azules (Teatro Regio, dirección de Luciano Cáceres, 2011), en el contexto de la fiebre amarilla de 1871, en una Buenos Aires desolada, aparece un "muchacho", mudo, hermoso, y al que el agua hirviente no quema. Demaría se vale de este personaje-jeroglífico, que conecta lo material con lo sagrado, como detonante de un thriller: su presencia evoca en el pintor y en la cuidadora de la iglesia la de dos muertos, una écuyère y un poeta, y pone metafóricamente a resonar todos los fantasmas de la historia argentina. De alguna manera, El cordero de ojos azules tematiza el mecanismo que observamos en el teatro de los muertos: el personaje-jeroglífico es el correlato de la poíesis, los personajes que recuerdan son el de los espectadores.

Finalmente, un caso en el que el teatro de los muertos se hace presente en la reescritura argentina de un clásico inglés del siglo XVII. Nos referimos a Los hechizados, pieza del dramaturgo y director Héctor Levy-Daniel estrenada en 2013, que, como aclara el programa de mano, está "inspirada muy libremente" en Lástima que sea una puta de John Ford (Londres, 1632). ¿Qué política de la diferencia impone Levy-Daniel a su reescritura? Algunos cambios están a la vista: el título; la recontextualización en la Argentina (de la Parma de John Ford, que mucho le debe a la Italia imaginada por Shakespeare y que se parece demasiado a Inglaterra, se pasa a la Pampa y a un tiempo histórico más cercano); la reducción del texto y del listado de personajes (Levy-Daniel se centra en la intriga de los hermanos incestuosos y desecha otras líneas secundarias presentes en Ford). Pero hay otros cambios más sutiles y singulares. Uno de ellos es el procedimiento del teatro de los muertos: Levy-Daniel le da la palabra a los muertos como una forma teatral de presentificación del ausente y del que no tiene voz, procedimiento de compensación simbólica y fricción política en una cultura como la argentina, donde en la dictadura el horror institucionalizó las desapariciones y habrá por siempre miles de cuerpos sin duelo. Así, por ejemplo, a diferencia de los muertos cuyos cuerpos han desaparecido (y esa desaparición los ha enmudecido incluso físicamente, porque ni siquiera sus restos pueden hablarnos), los personajes de Ada y su ama pueden referir su experiencia después de la muerte (aspecto que no está presente en la pieza de John Ford). Levy-Daniel hace referencia a otra desaparición (la de Amalia, la viuda seducida y amenazada por Toranzo, personajes correlato de Hippolita y Soranzo en el texto de Ford) y al crimen organizado, al "ejército de asesinos" (en las actividades de Toranzo y su ayudante, personaje siniestro que evoca a los integrantes de los "grupos 
de tareas" paramilitares).

En Latinoamérica, en los últimos años, dos libros trabajan en complementariedad con esta problemática del teatro de los muertos, aunque transitan otros caminos de análisis: Poéticas de lo cadavérico (2011), de la argentina Adriana Musitano, sobre teatro, plástica y videoarte de fines del siglo XX como "resistencia al olvido", y Cuerpos sin duelo (2013), de la cubana-mexicana Ileana Diéguez, sobre el que volveremos.

\section{Ampliación del concepto}

Pronto advertimos que el fenómeno no era privativo ni de la Postdictadura ni del teatro argentino, sino universal y de todos los tiempos. Según Marvin Carlson, "todas las culturas teatrales han reconocido, de una u otra forma, esta cualidad fantasmal, esta sensación de algo que retorna en el teatro, y así las relaciones entre teatro y memoria cultural son profundas y complejas. Así como uno podría decir que toda obra puede ser llamada Espectros [como la obra de Henrik Ibsen], con igual fundamento, uno podría argumentar que toda obra es una obra de la memoria" (The Haunted Stage, 2003, p. 2). Tal vez sea universal, pero todo parece indicar que ese mecanismo es contemporáneamente más efectivo que nunca. El director alemán Thomas Ostermeier afirmó en entrevista en la Escuela de Espectadores de Buenos Aires, con motivo de su magnífica apropiación shakesperiana presentada en el Festival Internacional de Buenos Aires de 2011:

Hamlet ama a su padre. Para él, el padre es un ejemplo que ilumina. Hay un buen libro de Jacques Derrida, Espectros de Marx, que para mí es la llave de la generación joven para entender Hamlet. Los espíritus de los hombres honrados nos envían un mensaje. Todo el cielo nos está gritando algo, pero somos pasivos. Y creo que ésta es la situación de Hamlet con el fantasma de su padre. En Alemania se dio una situación parecida a ésta después de la Segunda Guerra Mundial. Se corrompió todo el país. Y a nosotros, como tercera generación después de la guerra, la historia política nos está dando un mensaje. Y es que los muertos nos están llamando del pasado para reclamar venganza. Así leo el final de Hamlet: la real historia consiste en que la verdadera historia no va a ser contada. Ése es el horror (citado en DUBATTI, 2013b, la traducción es nuestra).

Para Ostermeier, Jacques Derrida también estaba preocupado por "los que regresan" -como Marx - a la memoria, aunque no necesariamente por la vía teatral. ¿Y acaso la afirmación de Carlson no vale para el conjunto de las expresiones artísticas, e incluso excede la esfera del arte? Baste recordar que en Espectros Ibsen observa a "los que regresan" en las múltiples herencias de la biología, la vida social, cultural, política. Justamente la fuerza del concepto del teatro de los muertos en la contemporaneidad está relacionado con la historicidad de su formulación: si hemos necesitado proponerlo es porque en el teatro de la Postdictadura argentina los muertos regresan y regresan a nuestra conciencia desolada bajo el trauma y las proyecciones lamentablemente aún vivas de la dictadura (DUBATTI, 2008a) .

De esta manera, el concepto del teatro de los muertos fue ganando en extensión y pasó a tener para nosotros también un sentido genérico: designa, en particular, el dispositivo poético de la memoria advertido en el teatro de la Postdictadura respecto de las experiencias y representaciones del pasado; en general, la inabarcable masa de teatro de quienes nos precedieron, el teatro que 
hicieron los ya muertos -artistas, técnicos, espectadores- y que, de alguna manera misteriosa, regresa cada vez que se produce un acontecimiento teatral. La memoria del teatro de los muertos se hace presente en cada nuevo acontecimiento. Por todo el teatro que hemos hecho y hemos visto, ya estamos nosotros también, los que aún vivimos, en el espesor histórico del teatro de los muertos.

\section{El teatro perdido: dos acepciones}

El concepto del teatro de los muertos se vincula estrechamente al de teatro perdido. Ya señalamos en Filosofía del Teatro I y II que la historia del teatro es la historia del teatro perdido (2007, parágrafos 73 y 74; 2010, passim, y especialmente parágrafo 13, corolario 12) y que inspiramos este concepto en el diálogo con Ricardo Bartís para la escritura de su libro Cancha con niebla (2003), al que justamente subtitulamos: Teatro perdido: fragmentos. Comprendimos el concepto de teatro perdido al analizar la resistencia de Bartís frente a la posibilidad de conservar su producción teatral (en libro, en video) y publicarla. La poíesis teatral es justamente aquello que no se hace texto, lo incapturable por el texto que acontece en el acontecimiento y no puede ser escrito. Y no nos referimos principalmente al teatro perdido que puede ser encontrado, sino al que por su entidad de cultura viviente está irremisiblemente perdido. La pérdida es constitutiva de la cultura viviente en tanto acontecimiento, y esto vale para el teatro, que no puede -en tanto acontecimiento- ser capturado en estructuras in vitro. Pérdida y función ontológica del teatro son inseparables. Distingamos entonces dos acepciones de teatro perdido.

Muchas de las piezas escritas por Lope de Vega se consideran hoy perdidas, pero aún pueden ser encontradas, y de hecho sucede, como en el caso del reciente hallazgo - para dar un ejemplo - del manuscrito de Mujeres y criados ${ }^{2}$. En nuestra investigación sobre el teatro de Pavlovsky encontramos tres piezas teatrales que autor y especialistas consideraban perdidas: Camello sin anteojos, Hombres, imágenes y muñecos y Circus-loquio (escrita en colaboración con Elena Antonietto), y las recogimos en el tomo VII del Teatro completo (2010) de Pavlovsky. Lo mismo nos ha sucedido con las obras La noche del forastero y Don Juan el almacenero de Alberto Vacarezza (2014), prolífico dramaturgo del que quedan todavía muchos textos inéditos por encontrar. La primera acepción de teatro perdido refiere, entonces, a textos (no sólo dramáticos) provisoriamente perdidos, que acaso pueden ser hallados. En este sentido juegan los términos "literatura perdida" y "literatura conservada" de la Antigüedad clásica según se desprende de cómo los emplea López Facal (en el epígrafe a este artículo). En una línea semejante, los citados R. M. Wilson y Alan Deyermond (véase en nuestro Filosofía del Teatro I, 2007) para la literatura medieval.

Pero hay un sentido mucho más radical de la pérdida: aquello que es incapturable y definitiva, inexorablemente se pierde, como la vida de los que han muerto. Lo único que podemos conservar o recuperar sobre los acontecimientos perdidos de la cultura viviente es información. Y entra aquí la vastísima cultura de la oralidad antigua, en referencia a lo afirmado por García Gual sobre el mito en parte conservado y en parte perdido (epígrafe). Y también el teatro como acontecimiento. No conservamos los acontecimientos teatrales del pasado, apenas algunos textos y escasa información adicional (escasa respecto de la relevancia del volumen de acontecimientos perdidos). En esta segunda acepción de teatro perdido, la pérdida es inseparable de la entidad ontológica (y de la función ontológica: poner un mundo a vivir efímeramente) del acontecimiento teatral.

2 Sobre la noticia del hallazgo de Mujeres y criados por el investigador Alejandro García Reidy, "Hallan obra inédita de Lope de Vega. En forma de copia manuscrita", Tiempo Argentino, Sección Cultura, 23 de enero de 2014, p. 35. 
Y no hace falta para comprender esta segunda noción irnos a la Antigüedad o a la Edad Media: basta con reflexionar sobre los acontecimientos teatrales del pasado inmediato o del presente que volátilmente se hace pasado ante nuestra conciencia, la función teatral de anoche, o la función teatral que vemos transcurrir mientras acontece el acontecimiento y, con vértigo, ya sabemos -mientras acontece- irremediablemente conducida hacia su pérdida. Cuanto más excepcional ${ }^{3}$ es el acontecimiento teatral, más sentimos la dimensión de la pérdida en el mismo momento en que estamos viviendo el acontecimiento, y mayor es el vértigo de la vida que se escapa.

\section{Actuación: pérdida y mito}

¿Cómo se conserva para su estudio el trabajo de un actor, el gran generador del acontecimiento teatral?4 Las grabaciones de audio o audiovisuales, las fotografías, sus notas y testimonios, nunca están a la altura de la complejidad de su trabajo en el acontecimiento teatral, lleno de infinitos detalles, resoluciones, matices y componentes simultáneos. El trabajo del actor, en tanto cultura viviente y acontecimiento, es incapturable en su complejidad. Por eso duele tanto la pérdida de un actor genial, como en el caso de Alejandro Urdapilleta, porque mientras vive se tiene la esperanza de volver a asistir a su producción de acontecimiento. La información que conservamos en soportes in vitro no alcanza para dar cuenta de su carácter prodigioso, e incluso puede atentar contra su memoria ${ }^{5}$ : insistamos en que el soporte in vitro no es el acontecimiento viviente, y que la actuación teatral sólo es plenamente tal en el acontecimiento viviente. Nos queda una única compensación frente a la pérdida de un actor prodigioso: la construcción de su mito. ¿Cómo? Manteniendo vivo el recuerdo de sus trabajos irremisiblemente perdidos, y no tratando de reemplazar esa pérdida con información in vitro. Pérdida y mito, felizmente, se llevan bien ${ }^{6}$.

\section{La memoria del teatro}

Ahora bien: a pesar de la pérdida de los acontecimientos poiéticos conviviales, hay una memoria del teatro, no tanto (y no sólo) en la deficiente información conservada, sino principalmente en la dimensión del teatro-acontecimiento como transmisión cultural. El teatro se mantiene vivo como institución, como biopolítica, como convención e invención, como poética (en su triple dimensión: estructura, trabajo, concepción), a través del entramado rizomático de la historia. El recuerdo de Urdapilleta no es sólo "cosa mentale", representación de la conciencia que evoca, sino que el arte de Urdapilleta se ha transmitido de alguna manera visible e invisible al arte de otros artistas: a sus cuerpos, a sus formas de resolver situaciones, a su manera de componer, a su mundo poético. Todo

3 Véase al respecto en nuestro Filosofía del Teatro III (2014), el capítulo “Excepcionalidad de acontecimiento: teatralidad singular del teatro".

4 Véase al respecto en nuestro Filosofía del Teatro III (2014) el capítulo “La construcción científica del actor desde una Filosofía del Teatro".

5 Muchas veces hemos proyectado videos o analizado fotografías sobre espectáculos del pasado, y esos registros resultan insuficientes para dar cuenta de la excepcionalidad de los acontecimientos teatrales.

6 No perderemos oportunidad de decir que la monumentalidad artística de Alejandro Urdapilleta no ha quedado registrada de ninguna manera en la traidora información de las grabaciones. Mientras vivamos, no perderemos oportunidad de alimentar su mito a través de expresiones del tipo: “¿Lo viste actuar a Urdapilleta? ¿No? ¡Te perdiste algo maravilloso!" o "Hay obras suyas que yo fui a ver tres, cuatro, siete, una decena de veces", "No hay palabras para expresar lo que te perdiste. Era un actor estremecedor...", etc. Por otra parte, nada más cerca de la verdad, ofrecida como testimonio. Creemos que, además de armar un archivo de información audiovisual sobre sus trabajos en teatro, cine, televisión y manuscritos, fotografías, en alimentar el mito Urdapilleta radica nuestro mejor homenaje y la única forma de calibrar y transmitir su grandeza artística en el futuro. 
acontecimiento teatral es un gran acto formativo: quien trabaja con Urdapilleta en escena, quien lo ve desde la platea, se están formando -lo quieran o no - o con él y esa formación se proyecta en futuros acontecimientos y legados. Así se han mantenido vivos la comicidad del sainete y el grotesco criollos, los saberes del teatro independiente, las enseñanzas que se implican y enlazan unas con otras, una forma más compleja de pensar los legados y la causalidad histórica de los acontecimientos teatrales. $\mathrm{Al}$ respecto recordemos a Jorge Luis Borges, quien escribió en "La poesía gauchesca" (Discusión, 1932): “Es fama que le preguntaron a Whistler cuánto tiempo había requerido para pintar uno de sus 'nocturnos' y que respondió: 'Toda mi vida'. Con igual rigor pudo haber dicho que había requerido todos los siglos que precedieron al momento en que lo pintó. De esa correcta aplicación de la ley de causalidad se sigue que el menor de los hechos presupone el inconcebible universo e, inversamente, que el universo necesita del menor de los hechos" (Obras completas I, 2007, p. 207). De acuerdo con Borges, pero seamos menos abarcadores: en la memoria del teatro se conservan muchos componentes pero otros también se pierden. Baste un ejemplo: ¿cómo se representaba ciertamente la tragedia griega en los siglos VI y V a.C.? ¿se ha transmitido esa memoria en el acontecimiento actual? En realidad no todo se conserva: el teatro opera territorial, regional, históricamente una selección de los componentes que carga su memoria, que tampoco escapa a la pérdida.

Más allá de la dimensión de pérdida inevitable, teatro de los muertos no quiere decir teatro muerto. El teatro está más vivo que nunca, especialmente porque cumple una función memorialista y de duelo (DIÉGUEZ, 2013). Pero también porque hay una memoria del teatro en los componentes que confluyen en el acontecimiento teatral: la reunión, los cuerpos, el espacio y el tiempo, la poíesis, la expectación, el principio de compañía y hermanamiento entre artistas, técnicos y espectadores en el convivio. Así entonces como observamos dos acepciones del teatro de los muertos y dos del teatro perdido, hay también dos dimensiones de memoria del teatro: podemos reconocer una memoria informativa, explícita, necesariamente incompleta y muchas veces desconfiable, constituida por los documentos, testimonios, materiales históricos conservados, la que puede atesorarse en una biblioteca, en una videoteca o en un museo ${ }^{7}$; hay otra memoria, más relevante por su significación en la vitalidad y el legado del teatro, que es práctica, está implícita en el hacer, una memoria viviente del teatro en el acontecimiento teatral y en todo aquello que confluye en el acontecimiento (cuerpos, miradas, ritmos, procedimientos y resoluciones, pedagogía, debates, información circulante, mitos, etc.).

\section{Cultura viviente y duelo. Problemas epistemológicos (I)}

Tal como ya señalamos en Filosofía del Teatro I y II, la entidad incapturable, imprevisible, en muchos aspectos incognoscible del acontecimiento teatral por su relación con la cultura viviente, plantea a la investigación teatral un "fracaso" anticipado que, siguiendo las palabras de Beckett, es necesario no tapar, hay que asumir y enfrentar para "fracasar mejor" (recuérdese la referencia a "Mal visto mal dicho" de Beckett y su Worstward Ho, en 1983 y 1997).

Esas limitaciones deben ser incorporadas a las condiciones epistemológicas para el conocimiento científico del acontecimiento teatral. Lo primero es hacerse cargo, porque de lo contrario, para poder controlar lo incontrolable, se lo transforma en un supuesto texto (inexistente como construcción final en el acontecimiento) de límites precisos, cognoscible, mensurable, predicable, sobre el que se puede aplicar un conocimiento exhaustivo y sistemático. El acontecimiento teatral es más que texto, y el texto que incluye es abierto, incapturable en su multiplicidad, híbrido, $7 \quad$ Empleamos el término en esta acepción en nuestro Filosofía del Teatro III (2014) en el capítulo "El artistainvestigador...". 
de límites imprecisos. El acontecimiento es reducido a texto por la voluntad desesperada del optimismo teórico de la Semiótica (sin duda por su resistencia a adecuarse al teatro). En Teatrología, entonces, hay que mirar de frente el objeto de estudio y hacer duelo frente a la pérdida, sin el placebo semiótico que sugiere engañosamente que estudiando el texto conservado o construido se comprende cabalmente el acontecimiento teatral. Hacer duelo implica asumir la muerte de la cultura viviente, el teatro perdido; aceptar que se puede conocer sólo aquello que realmente se puede conocer y tratar de pensar de la forma más inteligente lo que no puede ser conocido ("fracasar mejor"). Esa actitud proveerá sin duda una forma de conocimiento más ajustada, más realista respecto de la singularidad teatral. En términos de conocimiento científico, y retomando las referencias a Ricardo Piglia y Javier Daulte en Filosofía del Teatro III (2014, "Introducción” y parágrafos 2 y 28), se trata más bien de descubrir, observar y enunciar con una actitud realista lo que acontece en el acontecimiento más que de inventar un texto inexistente.

En este sentido el teatrólogo vive haciendo duelo: el sentimiento y la conciencia de pérdida irremisible forman parte de las condiciones epistemológicas del conocimiento del teatro, tanto para el artista y el espectador como para el científico. Estudiamos un objeto irremediablemente perdido: el teatro como acontecimiento. Ya no podremos volver a él sino a través de mediaciones incompletas que no son el acontecimiento y que por su cristalización traicionan su entidad efímera. El teatro, como ha señalado Ricardo Bartís, verticaliza la experiencia de la muerte. Por supuesto no hay una única forma de relacionarse con la muerte: habrá tantas como concepciones de teatro en el plano micropoético y en el de la poética abstracta (Filosofía del Teatro III, parágrafo 6). Cada base epistemológica implica una forma diferente de resolver la relación del teatro con la muerte. Pero la muerte no se puede ignorar, porque es constitutiva de la dimensión de acontecimiento viviente. Y aquí surge una diferencia raigal entre la Semiótica y la Filosofía del Teatro. La Semiótica realiza, en el sentido freudiano, "trabajo de duelo" (Freud, Duelo y melancolía, 1979), y logra sustituir un objeto perdido (el acontecimiento) por otro objeto (el constructo de análisis sígnico), realiza en esa sustitución una compensación, logra olvidar la pérdida del acontecimiento a través de la ilusión de conservación de un objeto hecho de signos (los textos de la palabra, o de la palabra-imagen-sonido fijados en soportes in vitro que pueden ser conservados, o del análisis construido). La Semiótica, como la literatura y el cine, creen que logran vencer a la muerte, o al menos reparar el dolor que produce la muerte. Por el contrario, la Filosofía del Teatro, como el psicoanalista Jean Allouch (Erótica del duelo en tiempos de la muerte seca, 2006), cuestiona esta ilusión: no puede haber olvido del duelo, ni sustitución, porque la pérdida del acontecimiento se realiza sin compensación alguna, es pérdida "a secas" (2006, p. 9). Ileana Diéguez, en Cuerpos sin duelo, analiza la teoría de Allouch y sintetiza: "El duelo, en opinión de Allouch, no puede ser reducido a un trabajo. Sumándose a la crítica realizada por Philippe Ariès, según la cual ‘Duelo y melancolía' prolonga una versión romántica del duelo, Allouch pone en duda el poder sustitutivo del nuevo objeto que hará olvidar el 'objeto perdido' (...) Y pone como ejemplo de esa no sustituibilidad la resolución de Antígona -citada por Lacan en sus seminarios de mayo y junio de 1960- negándose al reemplazo del objeto de su amor y de su dolor" (2013, p. 176).

La Filosofía del Teatro propone entonces no generar ilusiones de sustitución ni olvidar la pérdida del acontecimiento, asumir el duelo y hacer de la asunción de la pérdida una nueva potencia de conocimiento. Apropiándose de la teoría de Allouch sobre el duelo, podemos afirmar que la conciencia del teatrólogo respecto de la relación inseparable entre acontecimiento teatral, cultura viviente, muerte y pérdida, "se acompaña de una transformación de la relación con la muerte" (ALLOUCH, 2006, p. 333) que, como afirma Diéguez, constituye "un acto que deja al deudo habitado por sus muertos" (2013, p. 177). En este sentido pueden leerse las palabras de Mónica López Ocón: "Estamos condenados a volver a enterrar a los mismos muertos" (epígrafe en este capítulo). En 
términos ontológicos, tanto el teatro como el acto de duelo del teatrólogo son dos acontecimientos que no se libran de la muerte ni del dolor de la pérdida. Retomemos la palabra de Diéguez sobre el pensamiento de Allouch: "Esta noción de duelo que propone Allouch también está en deuda con Kenzaburo Oé [Agwil el monstruo de las nubes, de Dinos cómo sobrevivir a nuestra locura], para quien el duelo no es reemplazar al muerto sino cambiar su relación con él, sacrificando algo. El duelo es entonces como un acto - ya no un trabajo - que reconoce una pérdida sin compensación alguna, pues el duelo no es perder 'un objeto', sino 'perder a alguien perdiendo un trozo de sí' (ALLOUCH, 2006, p.401), en el sentido de que el muerto se va llevándose un pequeño trozo de los que siguen viviendo" (2013, p. 177). La Semiótica logra olvidar, sustituye, reemplaza el acontecimiento teatral; la Filosofía del Teatro asume su pérdida como pérdida de un trozo de la propia relación con el mundo, de la propia existencia.

¿Tendrá que ver la singularidad del teatro de Buenos Aires, sus poéticas, la fuerza de sus convivios, la valoración del teatro como patrimonio, el clima teatral, con la aceptación de base de esa transformación de la relación con la muerte? Como decíamos al comienzo del presente artículo, el teatro de Postdictadura está poblado de muertos y de alguna manera la asistencia al convivio y la relación con el teatro como cultura viviente ayuda a asumir la experiencia del duelo y a transformar la relación con la muerte.

Sin duda, es este núcleo, la transformación de la relación con la muerte, una de las razones de la potencia del teatro en la Argentina, de la necesidad nacional del teatro, como alguna vez propusimos en diálogo con Santiago Sánchez Santarelli (2009). Como dice Postales argentinas y buena parte del teatro de Ricardo Bartís ${ }^{8}$, la Argentina "ha muerto" en la dictadura, la mató la dictadura, ya no existe o al menos ya no podrá ser la misma, y el gran acto de ratificación ritual de nuestra existencia es la teatralidad desde el cuerpo viviente. Por eso la Argentina se transforma en una especie de laboratorio de teatralidad social en la Postdictadura: para sostener que mientras los cuerpos viven, seguimos viviendo, y a la vez sostener desde la relación cultura viviente-muerte el duelo por el país muerto. Es por eso, acaso, también, que hoy el país tiene un nuevo pensamiento teatrológico. La Argentina no está pensando el teatro como se piensa en Europa o en Estados Unidos, básicamente por una razón de peso: hemos adaptado el pensamiento teatral a las prácticas teatrales. Pensamiento cartografiado; cartografía radicante (Filosofía del Teatro III, “Introducción” y especialmente parágrafo 20). El teatro asume la muerte de/en la Argentina, y de alguna manera la transforma en el acto del duelo. La Argentina renace en la autoafirmación de la cultura viviente, de allí el sentido raigal que constituye al convivio en acontecimiento político.

\section{Ignorancia, destrucción. Problemas epistemológicos (II)}

Epistemológicamente, la transformación de nuestra relación con la muerte en el teatro nos lleva a problematizar tres formas de ignorancia como una vía beckettiana de "fracasar mejor" en la producción de conocimiento científico, es decir, avanzar en el conocimiento teatral desde la aceptación de los límites, no desde su negación.

Confrontamos, entonces, el duelo de lo provisoriamente perdido y el duelo de lo irremisiblemente perdido: son muy diferentes. En cuanto al acontecimiento teatral y la cultura viviente, está provisoriamente perdido todo lo que podemos recuperar como información indirecta

$8 \quad$ Véase al respecto en Filosofía del Teatro III el capítulo "El artista-investigador, el investigador-artista, el artista y el investigador asociados, el investigador participativo: Filosofía de la Praxis Teatral", especialmente el parágrafo 26. 
respecto del acontecimiento (textos, imágenes, objetos, espacios, etc.), pero está irremediablemente perdido lo que no podemos recuperar: ni la vida ni el acontecimiento en su entidad ontológica.

El duelo teatrológico obliga a asumir un límite en el conocimiento, una ignorancia necesaria. Debemos distinguir entre ignorancia pasiva y activa. Llamamos ignorancia pasiva a aquella que no se reconoce como ignorancia, que no es consciente de sí. Ignorancia activa, por el contrario, es aquella que construye su conocimiento sabiendo lo que ignora, lo que no puede conocer asumiendo el límite o, paradójicamente, eligiendo ignorar lo que sabe. De aquí se desprenden tres principios fundamentales para el ejercicio del duelo teatrológico desde una ignorancia activa:

- Todo lo que pueda conocer (sobre el acontecimiento teatral), no lo puedo ignorar.

- Una vez conocido cuanto puedo conocer, puedo elegir ignorarlo.

- Una vez reconocido lo que no puedo conocer (del acontecimiento teatral), debo transformar esa limitación en una condición epistemológica.

De acuerdo al primer principio, el investigador debe multiplicar todos los esfuerzos por conseguir documentos, testimonios, información variada, objetos, etc., vinculados al acontecimiento teatral perdido, como una forma de erradicar la ignorancia pasiva. Por el segundo principio, una vez que he accedido al máximo conocimiento posible, puedo descartar esos saberes (ya conocidos) para colocar el eje en lo vacante (no necesito ni debo quedarme solamente en lo que puedo conocer). Por último, el tercer principio expresa la quintaesencia del "fracasar mejor": enfrentado al límite, debo pensarlo como condición epistemológica para acceder a fundamentos sólidos de la Teatrología.

Olvidar el acontecimiento teatral y sustituirlo por otro objeto no son acciones que carezcan de consecuencias. El problema de no reconocer los límites del conocimiento sobre el acontecimiento es la destrucción del acontecimiento bajo la ignorancia pasiva o la negación del límite. La no intelección de la singularidad ontológica del acontecimiento, de su relación transformadora con la muerte y con la cultura viviente, equivale a la destrucción del objeto teatrológico. La destrucción del acontecimiento significa una multiplicación de la muerte no como vía de comprensión de la cultura viviente, sino contra la cultura viviente. Esa muerte atenta contra el teatro y el arte: encarna el gesto contrario al compañerismo, en el sentido de compañía (Filosofía I y II, passim; Introducción a los estudios teatrales. Propedéutica, passim ${ }^{9}$ ). La destrucción es otra forma de la puesta en acción del pensamiento antiteatral, por extensión artiartístico (Filosofía del Teatro I, parágrafo 57). Formas de destrucción: la indiferencia hacia el acontecimiento teatral, la negación a ir al teatro, la ceguera axiológica hacia su significación en la cultura argentina ${ }^{10}$; el ejercicio de una crítica o una investigación mediocre (lamentablemente demasiado frecuente), que degrada el acontecimiento desde una visión inadecuada a su singularidad y deja registro escrito de esa visión cuando el acontecimiento irremisiblemente muere (y ya no podrá valerse de sí mismo para defenderse); el boca-en-boca negativo de un público no formado, que sin reconocer los valores del acontecimiento atenta deliberada o involuntariamente contra la convocatoria al convivio, recomendando no asistir ${ }^{11}$

9 En este último, pueden consultarse las numerosas observaciones sobre el concepto de compañía en el “Índice de conceptos y referencias teóricas" (Dubatti, 2012a: 164).

10 Nos gusta repetir en los medios, a manera de "marca" de crítico, que nos sorprende que en Buenos Aires haya gente que no vaya al teatro, porque el teatro es una de las formas artísticas en las que Buenos Aires nivela internacionalmente. Nuestro latiguillo es: "Vivir en Buenos Aires o pasar por Buenos Aires y no ir al teatro, es como vivir o pasar por New York y no ir al MOMA, o vivir o pasar por Barcelona y no conocer La Sagrada Familia de Gaudi".

11 Nos ha sucedido, incluso en la Escuela de Espectadores, que muchos integrantes de la Escuela no aprecien un espectáculo recomendado por sus valores, y hagan circular entre los alumnos que aún no lo han visto que "no vale 
; el impedimento de hacer obra, de generar acontecimiento, por diversas vías, sea la censura (como en dictadura), la persecución (incluso en democracia), el atentado (pueden encontrarse múltiples ejemplos de destrucción en la historia del teatro argentino; véase al respecto nuestro Cien años de teatro argentino, Dubatti 2012b); privilegiar la atención sobre un aspecto del acontecimiento teatral por sobre otro. En cuanto a lo último, por ejemplo, históricamente se ha privilegiado el teatro como "literatura para leer" y se han conservado fundamentalmente los textos dramáticos, en desmedro de la música, las grabaciones audiovisuales, las fotografías, las plantas de luces, los diseños de vestuario y escenografía, los borradores y textos parateatrales y cuadernos de bitácora, etc. Afirma Jorge Bergua Cavero sobre la tragedia clásica como espectáculo integral: "Mientras que hemos conservado, en mejor o peor estado, el texto de las obras teatrales, es muy poco lo que sabemos sobre su coreografía y su música (...) en cualquier caso, los responsables principales de la pérdida de las melodías fueron los sabios alejandrinos, que al ocuparse de fijar los textos canónicos de los poetas trágicos (y de otros poetas) se desentendieron por completo de aquellas, ya que su interés principal radicaba en el lenguaje y la trama de las obras" (2006: XV). Algo parecido puede decirse sobre nuestro sainete musical, del que se conservan miles de textos y escasas partituras. Es relevante, en consecuencia, que el investigador tome conciencia epistemológica del efecto destructivo (sin duda nocivo) que puede estar produciendo respecto de los acontecimientos teatrales desde una praxis investigativa no adecuada.

\section{Tematización del límite y la destrucción en las mismas piezas teatrales.}

\section{Necesidad de sentar memoria}

El teatro reflexiona permanentemente sobre sí mismo, generalmente de manera oblicua o secreta, es decir, sin mostrarse evidentemente como metateatro, y construye metáforas que tematizan los complejos vínculos con la cultura viviente y la muerte. En los últimos años varias obras argentinas han tematizado el límite frente al conocimiento de la cultura viviente y al problema de la destrucción del arte. ${ }^{12}$

El punto de partida de la historia que cuenta Fauna (2013), la más reciente creación de Romina Paula, es la filmación de una película sobre una extraña mujer que vivió en la selva misionera. Fauna, así se llamaba esa mujer -con toda la potencia del símbolo-, es una summa de civilización y barbarie, de primitivismo y cultura, mezcla de animal salvaje y de sofisticada artista que se disfraza de hombre (Fauno) para poder participar en un círculo literario y que, travestida en varón, seduce a uno de los hombres de su vida. Una actriz y un director de cine viajan a la casa donde vivió Fauna y

la pena ir a verlo, sólo le interesa a Dubatti". El efecto puede ser mortífero, ya que llega el día de la clase de análisis de dicho espectáculo -para nosotros valiosísimo-, con asistencia de los artistas, y muchos alumnos se han abstenido de verlo. La Escuela funciona hace catorce años y nos ha pasado que espectadores que "odiaron" (el término les pertenece) una de nuestras recomendaciones e hicieron boca-en-boca negativo dentro de la Escuela, años después nos agradecen haberlo visto y nos dicen: "Recién ahora comprendo por qué nos mandaste a ver ese espectáculo". Nos ha pasado, por ejemplo, con Mil quinientos metros sobre el nivel de Jack de Federico León, La Orestíada dirigida por Romeo Castellucci, La estupidez de Rafael Spregelburd, La Gran Marcha de Eduardo Pavlovsky, entre muchas otras. Por eso escribe García Lorca: “Al público se le puede enseñar -conste que digo público, no pueblo-, se le puede enseñar, porque yo he visto patear a Debussy y a Ravel hace años, y he asistido después a las clamorosas ovaciones que un público popular hacía a las obras antes rechazadas. Estos autores fueron impuestos por un alto criterio de autoridad superior al del público corriente, como Wedekind en Alemania y Pirandello en Italia, y tantos otros. Hay necesidad de hacer esto para bien del teatro y para gloria y jerarquía de los intérpretes" ("Charla sobre teatro", Obra completa, tomo VI, 2008: 429).

12 Preparamos actualmente un artículo sobre el tema, centrado especialmente en ejemplos del período postneoliberal (2003-2014). 
toman contacto con sus hijos para obtener más información y pedirles que colaboren en el proyecto de la película. Pronto la historia de la filmación se confunde y fusiona con la historia de las relaciones personales entre estos cuatro personajes. Los planos se multiplican, interactúan, se desdelimitan. La brillante escenografía de Alicia Leloutre y Matías Sendón evoca deliberadamente una hacienda selvática y un set de filmación / estudio de grabación de efectos sonoros, rodeado por grandes focos. Pronto el espectador deberá asumir la perturbación que le produce no saber bien qué está viendo (la infrasciencia, el no-saber como condición de relación con el espectáculo, es justamente un rasgo característico de este nuevo teatro): si la materia del film es Fauna o las conexiones interpersonales de los responsables de la película mientras buscan a Fauna. Esto es, si se trata de una película sobre su propio hacerse, el documental sobre la historia del documental, o la ficción sobre la producción de la ficción, que en realidad se experimenta como una obra teatral atrapante. El gran tema de Fauna radica en la reflexión sobre las relaciones entre arte y vida, a la vez nítidas y borrosas, y sobre la imposibilidad de apresar la cultura viviente, especialmente cuando la vida ha dado paso definitivamente a la muerte. Si el arte es hoy el lugar donde construimos nuestra relación con la realidad; si el arte es la usina de producción de sentido que necesitamos para construir el sentido que la realidad mediática se empeña en disolver, Fauna se ofrece como un magnífico observatorio ontológico, es decir, como un espacio para detonar en el espectador las preguntas esenciales sobre cómo establecemos relaciones de multiplicación entre arte y realidad. Y, en consecuencia, por qué necesitamos imperiosamente del arte para vivir. Esta puede ser una de las razones de por qué en Buenos Aires tantas obras teatrales de los últimos años hablan explícitamente sobre el arte. Fauna plantea que investigar la vida de una persona y proponerse transformarla en una película generan algunas preguntas acuciantes: ¿en qué se diferencian el arte y la vida, que ya Aristóteles separó en su Poética en el siglo IV a.C.?; ¿en qué se identifican o se asemejan?; ¿qué es aquello de la vida que el arte no puede representar, como afirma el hijo de Fauna cuando habla de la muerte de las yeguas atacadas por las abejas?; ¿un personaje es lo mismo que un hombre, o como escribió Arlt en Saverio el cruel -citado en la obra- "cien fantasmas no valen un hombre"? "No hay tal cosa como contar la historia de una vida, eso es para gente que no sabe vivir. ¿Por qué no cuenta su historia si no, la de su vida, algo de lo que tenga algo de idea?", dice el hijo de Fauna. ${ }^{13}$

La veta de oro del mirador ontológico se abre infinitamente. ¿Vivimos de otra manera a través del arte, como cuando la actriz asegura que "solo puedo acercarme a ese dolor a través de la ficción"? ¿Cómo se vinculan ser y contar? ¿Qué diferencia hay entre la verdad de la historia de una mujer, la mentira y las versiones sobre su vida? ¿Cómo pueden el hijo y la hija de Fauna tener miradas tan diferentes sobre acontecimientos de la existencia de su madre? ¿Es el mito una forma de mundo alternativa a la naturaleza de la realidad y del arte, que amplía nuestra experiencia en otra dirección, como sostiene Paul Ricoeur? Paula incluye en su obra el mito de los jóvenes hermanos transformados en cisnes por el hechizo de su madrastra (relato metadramático), y cuando recuperan su forma humana "la gente asiste al milagro en silencio": como en la función de Fauna. Y finalmente la gran pregunta, aquella sobre nuestra (in)capacidad de conocer y distinguir: el director le pide a la actriz que actúe "esa ambigüedad" entre la verdad, la mentira, el mito y la ficción propia de la realidad, y la didascalia del texto se hace cargo de la limitación de nuestras posibilidades: "Todo es muy confuso", escribe Paula. Para el autor, para el espectador, para los actores... Paula nos enfrenta con el límite, así en el arte como en la vida.

Los talentos (2011) de Walter Jakob y Agustín Mendilaharzu propone el intento de una mirada comprensiva, dadora de valor sobre el mundo. Una mirada que desplaza la ironía nihilista posmoderna por la ancestral comicidad de carácter, y recupera el interés intelectual y la emoción 
que producen el espectáculo de la existencia humana y su potencia creadora. Donde otros predican el "desierto de la realidad", Los talentos invita a reconocer una ontología humana, una realidad construida por los hombres, la realidad comprendida como el infinito tesoro de los talentos humanos, de los que el mundo es morada y también puede ser pérdida. Para expresar esa infinita riqueza, Los talentos rescata un repertorio de procedimientos dramáticos tradicionales (¿dónde hallar las ideas posdramáticas de Hans-Thies Lehmann en este teatro?), hunde sus raíces en el pasado, pone el lenguaje al servicio de la expresión de una cosmovisión vital, y hasta se reserva unas palabras finales que, sin ser "aleccionadoras", orientan al espectador en la identificación valorizadora de esa riqueza. Una suerte de neoexistencialismo que atesora el mundo de lo humano con un gesto sensible y positivo -en la mejor tradición de la mirada del Humanismo originado en el Renacimiento-, atravesado por la contemporaneidad, pero con resonancias arcaicas en puente hacia el pasado remoto de la cultura occidental. Paradójicamente, Los talentos insiste en que al hombre le cuesta superar la experiencia de lo particular y concreto, que no puede llegar a comprender el mundo como totalidad, apenas si intuye algunas partecitas, pero que en la diferencia y diversidad de esas porciones de mundo se inscribe lo esencial. Lo propio del hombre es vivir, construir y percibir en un mundo de inmediatez, complejo y pequeño, pero esa limitación inscribe lo esencial y deja ver otros mundos más allá. Una escala humana borgeana, a la vez pluralista y esencialista: el universo no existe como un todo, hay universos particulares, pero cada hombre es a su tiempo El Hombre. ¿Qué mejor manera de encarnar esa mirada que asumir el punto de vista de dos muchachos de 20 años, Ignacio y Lucas, entre la adolescencia y la primera juventud? ¿Puede haber un carácter cómico más pregnante en términos teatrales que un adolescente, y más aún el de un grupo de adolescentes amigos? Y más si estos adolescentes son cachorros de artistas, creativos, "talentos". El dúo inicial se multiplica en facetas al triangularse con Pedro. Y el universo adolescente se hace más nítido al contrastar con otros universos, cuando se suma a la escena Denise, de 25 años, la hermana de Pedro. La adolescencia masculina se contrasta con el mundo de las mujeres y el de los jóvenes más "grandes". Asomándose al universo de Ignacio, Lucas y Pedro, Denise duplica la mirada del espectador: es el testigo. La obra sugiere que el pasaje de la adolescencia a la juventud (en el camino hacia la adultez) está en el conocimiento del amor. Por eso el gran articulador de la acción y los parlamentos es el ars amandi, el arte de amar, de Ovidio al Arcipreste de Hita, o, dicho en porteño por ellos: "las técnicas para levantar minas"14. En tanto adolescentes, Ignacio y Lucas tienen una edad intelectual y otra edad afectiva, poseen la condición teatral por excelencia del que está en tránsito, en conflicto, en situación de prueba, cambio y aprendizaje. Son una mezcla distante y entrañable de sabiduría y torpeza, inteligencia y trivialidad, autoconciencia y patetismo. Como el mundo es difícil de aprehender, están todo el tiempo "sherlockeando", y a la vez se sienten amenazados por el secreto de los adultos.

La obra da una clave para entender su poética: el poema de Lucas "Ejemplo de los Budas de Bamiyán", basado en una noticia leída en el diario. Ignacio y Lucas explican que "Afganistán ahora está gobernado por una especie de sacerdotes híper fundamentalistas que se llaman los talibanes (...) estos talibanes usan el Corán como constitución. El Corán prohíbe que haya representaciones de otras deidades. Entonces los talibanes estos anunciaron que van a dinamitar unos budas colosales que hay, esculpidos en roca en la ladera de una montaña, en el valle de Bamiyán. Y hubo protestas en todo el mundo, pero nadie sabe qué hacer para frenar la inminente destrucción (...) es algo terrible, son excelentes los budas estos. Los ves y te caen mil puntos. Sonrientes, majestuosos, arrogantes... son del siglo quinto, son las imágenes de Buda más grandes que se conservan". El poema de Lucas es un apólogo -a imitación de los del Libro del Buen Amor- pero necesariamente le falta el cierre: es un apólogo sin final ni moraleja. "Una forma arcaica -analizan- adaptada a un tema actual", pero en la que la pedagogía antigua es imposible. Los talentos es un apólogo sin moraleja, es decir, una parábola comprensiva sobre el mundo, que encierra sentido, pero sin cierre didáctico. A Jakob y Mendilaharzu 14 Citamos el texto de Los talentos a partir del original inédito, sin paginar, cedido por los autores. 
les pasa con su obra Los talentos lo mismo que a Lucas: “No estoy seguro de saber de qué es ejemplo mi 'Ejemplo de los Budas de Bamiyán'”. Sin embargo, Ignacio da una posible clave para imaginar el final del poema: "Si [los talibanes] deciden volarlos [a los Budas], que se dispongan a morir en su ley, sonriendo con esa sonrisa tan bella que tienen. Eso, que sonrían. Que no se arrepientan de nada. Que miren al mundo desde su altivez y le digan que, cuando ellos desaparezcan, van a desaparecer también todas las cosas que ellos vieron, toda esa riqueza infinita, la memoria de siglos y siglos. Que se va a perder para siempre esa manera tan única y hermosa de mirar al mundo. Y que el mayor daño no lo van a sufrir los Budas, que habrán muerto, sino el mundo". Los talentos es un apólogo abierto, sin moraleja, pero con una invitación a los espectadores: no hay moraleja para que volvamos a construir cada vez el mundo con nuevas miradas y sentidos. La pérdida de los Budas es la metáfora de la pérdida del arte, por violencia, en este caso, y perder el arte es perder "esa riqueza infinita, la memoria de siglos y siglos". El arte perdido implica el duelo en el sentido de Allouch: una transformación de la relación con la muerte.

Otras obras recientes que tematizan la destrucción son Absentha (2011) de Alejandro Acobino (en la que un grupo de integrantes de un taller literario, exclusivamente formado por varones, se transforma en un comando de sabotaje a recitales de poesía) y El fin del arte (2013, todavía no estrenada) de Rafael Spregelburd, quien retoma el episodio del Cristo de Borja,en Zaragoza, destruido por Cecilia Giménez.

A pesar de las dificultades que genera la incapturabilidad del acontecimiento teatral y contra la destrucción que tanto ha padecido y sigue padeciendo el teatro, es necesario sentar memoria (recordemos el concepto de "sentar" y "sentación" desarrollado en Filosofía del Teatro II (parágrafos, 4, 16 y 28), vinculado a la noción de producción de acontecimiento y habitabilidad en el acontecimiento). De allí la importancia de los archivos y los centros de documentación (sobre los que ha creado una conciencia cada vez mayor entre los teatristas el Instituto Nacional de Teatro), y también de la producción y conservación del relato de experiencia, de la memoria y del pensamiento teatral. A la vez, la pregunta: ¿cuánto podemos salvar?, ¿y cómo? Se trata, de todas las formas posibles, de no propiciar la pérdida, de conservar lo que podamos conservar, de no contribuir al naufragio del teatro perdido. Que sólo se pierda aquello que, por su singular ontología de cultura viviente, está destinado a perderse, y que se salve todo lo que pueda ser salvado. Porque si no, parafraseando a Los talentos, "se va a perder para siempre esa manera tan única y hermosa de mirar al mundo. Y que el mayor daño no lo va a sufrir el teatro, que habrá muerto, sino el mundo".

\section{Construcción de ausencia y presencia; su integración en el espesor ontológico del acontecimiento}

Para la edición de las Obras completas de William Shakespeare (Dubatti 2006b) entrevistamos al director y pedagogo Raúl Serrano, recordemos qué nos dijo sobre Rey Lear ${ }^{15}$ : “Tengo claro cuál es para mí la mejor escena del mundo. Está en King Lear ${ }^{16}$. A Gloucester le han sacado los ojos, y sale a la intemperie, ciego, ensangrentado, decidido a matarse. Allí se encuentra con su hijo Edgar. Este no sabe qué hacer al ver a su padre en ese estado, tiene que reprimir su dolor y se hace pasar por otro, por un loquito. Gloucester le dice que cree reconocer su voz y Edgar, para no ser descubierto, dice más tonterías. El padre le pide que lo lleve a la más alta montaña y el hijo le miente: le dice que sí pero lo conduce por el llano. Lo hace subir a un montículo de veinte centímetros y le hace creer que

Véase también en "Singularidad de la poíesis teatral: el cuerpo en acción" (Filosofía del Teatro I, parágrafo 
está al borde de un precipicio. El público y Edgar están viendo lo que Gloucester ciego no ve: que va a saltar sólo veinte centímetros. Gloucester le pide a Edgar que se aleje, el hijo le hace creer tal cosa. Gloucester dice sus últimas palabras y se tira, cae y se pregunta ‘Será esto la muerte?', y el hijo que siempre estuvo a su lado, asumiendo otra voz, le cuenta que lo vio caer desde tan alto pero leve, como si su cuerpo fuera de plumas... Esto se llama convención teatral, y demuestra que Shakespeare sabía como nadie que la convención y la imaginación son la sustancia de base del teatro. Y si querés comprobarlo, basta con leer el prólogo a Enrique V: 'Suponed que dentro de este recinto de murallas están encerradas dos poderosas monarquías (...) Suplid mi insuficiencia con vuestros pensamientos. Multiplicad un hombre por mil y cread un ejército imaginario'. Este es el secreto de Shakespeare: un teatro que está dispuesto a usar lo mejor de la literatura, que pone el cuerpo a imaginar estas conductas, delante del público que participa de la convención y que al mismo tiempo no puede dejar de sufrir por el drama del padre y del hijo, ¡mientras se divierte!... Decime si hay alguna escena en el mundo que sea más teatral, si la palabra teatral quiere decir algo... Convención e imaginación: la esencia del teatro occidental" (p. 59).

Serrano pone el acento en que, gracias a la convención que estimula la imaginación, en escena sólo es necesario un espacio vacío, sin despliegue de materialidad escenográfica (como se hacía en The Globe y otros teatros renacentistas en Londres), en el que la presencia del cuerpo del actor, a través de su acción física y verbal (que contiene la literatura), hace que el espectador imagine la situación de tortura, el intento de suicidio, los personajes y los juegos de identidad, el acantilado de Dover, e incluso la no concretada caída de Gloucester como si su cuerpo fuera de plumas... Todas las locaciones y los niveles más variados de representación ficcional en un espacio vacío. Un cuerpo presente en el convivio que genera en los espectadores poderosas representaciones de objetos, espacios, personajes, situaciones y tiempos ausentes. Un ausencia infinita, ilimitada, un tesoro de representaciones que se construyen en la conciencia del espectador, porque ninguno de ellos acontece en la escena, sino en la cabeza del espectador. Y en cada espectador de manera diversa y en permanente metamorfosis y mezcla, según el grado de convencionalización de la referencia (Harshaw, 1984). Retomamos entonces el término que empleamos al comienzo de este capítulo: el teatro trabaja con dispositivos de estimulación, que no sólo estimulan la memoria (como ya señalamos arriba), sino fundamentalmente la imaginación del espectador.

El mismo recurso a la convención es registrado en el teatro griego clásico, como lo señala Bergua Cavero sobre la representación de la tragedia en las fiestas del siglo V a.C.: "Otro aspecto digno de destacarse es el hecho de que los actores fueran siempre varones, interpretasen más de un papel en la misma pieza y además fuesen provistos de una máscara; si a esto añadimos el uso de un decorado elemental, se advierte hasta qué punto el público ateniense estaba dispuesto a aceptar un grado de convención dramática mucho mayor que el público en el teatro moderno, por no hablar del espectador de la era del cine y de los efectos especiales" (2006: XII). Eli Rozik (2002), Lucas Margarit (2013) reflexionan sobre el cross casting (el actor que representa un personaje de otro sexo) y el artificio de manifestación evidente que, sin embargo, genera ilusión en la actividad imaginaria.

Para que haya poíesis teatral lo ausente debe encontrar su generación en la acción del cuerpo presente, interviniendo convivialmente en la territorialidad del cronotopo cotidiano. Si bien los estudios teatrales, por la vía semiótica, han valorado especialmente lo ausente generado a través de los signos, la Filosofía del Teatro sostiene que tanto más potente que la ausencia es la presencia humana en el convivio. Sin duda el espectador construye en su imaginación lo ausente, pero también percibe lo presente y cruza presencia y ausencia en el espesor del acontecimiento poiéticoconvivial-expectatorial. Vamos al teatro no sólo a tomar contacto con las ausencias, sino también -y primordialmente- con las presencias. He aquí una de las diferencias fundamentales entre el teatro 
y el cine. La ausencia es infinita, pero en el teatro la presencia no es menos ilimitada: llamamos presencia a todo lo que concurre a la zona de acontecimiento como materialidad y como fundamento de esa materialidad. En la presencia teatral, gracias a los cuerpos, el espacio y el tiempo, ingresa el ente metafísico por excelencia, la vida, la existencia, lo real, como presencia que es condición de posibilidad de la materialidad del convivio.

En el convivio, el espectador se pregunta por la presencia de los artistas, de los técnicos y los espectadores, por los cuerpos, el espacio, el tiempo, por la misteriosa posibilidad de estar allí reunidos. ¿Quién está en la escena produciendo poíesis?, ¿por qué?, ¿qué significa para él/ella/ellos (el grupo) hacer lo que hacen?, ¿cómo lo hacen, como trabajan en escena y cómo han trabajado en el proceso?, ¿cómo se han formado para llegar hasta allí?, ¿cuál es el vínculo entre eso que hacen y su vida cívica?, ¿qué les pasa a los espectadores en el convivio?, ¿de dónde vienen los aquí reunidos, qué vidas han atravesado hasta llegar a esta reunión?, ¿cómo juegan esas vidas en la fundación de la zona teatral?, ¿qué me pasa a mí, qué a los otros, cómo los otros me influyen? La reunión de presencias integra inseparablemente el espesor ontológico del acontecimiento. Según los procedimientos estructurales, el trabajo y la concepción, la ausencia y la presencia en el espesor ontológico del acontecimiento varían y constituyen poéticas diferentes. Según la poética, los elementos presentes en el convivio y los ausentes (presentes en la imaginación) cambian; para una visión cristiana, la escena inscribe los trascendentales del ser (Bien, Belleza, Verdad) como correlación divina; para la concepción hierofánica artaudiana, la escena manifiesta el manas (DUBATTI, 2008b); para la concepción posmoderna, la escena es un juego de lenguaje a través del intercambio de signos. La complejidad de presencia y ausencia en el espesor ontológico del acontecimiento está en la base, en el origen de todo acontecimiento teatral. Ausencia y presencia deben ser pensados en su diferencia tanto en la praxis teatral de Tespis como en la del drama litúrgico o en la del drama moderno. Ausencia y presencia deben ponerse en correlato con las nociones de representación, presentación y sentación, siempre vigentes en todo acontecimiento teatral, de Sófocles a Dario Fo.

La presencia es múltiple: no sólo se manifiesta en la reunión de los cuerpos en el cronotopo cotidiano: también están presentes el cuerpo poético en tanto acontece y mientras acontece, y la zona teatral que funda la dinámica del convivio, la poíesis y la expectación. La presencia sienta una zona de experiencia territorial ${ }^{17}$. Sólo está ausente aquello cuya referencia es instaurada por los signos, las referencias de los que hemos llamado signos de otro en sí (cuerpo semiótico II) y signos de signo (cuerpo semiótico III). El cuerpo presemiótico está presente en el acontecimiento como condición de posibilidad de la presencia de los signos en escena. La presencia del cuerpo de acontecimiento genera su manifestación fenomenológica, pero además genera lo que hemos llamado signos de presencia; la presencia es manifestación fenomenológica y constituye a la par signos de presencia.

Volver a pensar la presencia y otorgarle su centralidad en el acontecimiento teatral significa restituirle al teatro su poder humano y político, su peligrosidad de incidencia social y de cambio. El convivio, la reunión de la cultura viviente, como acontecimiento político en sí mismo. Es ir más allá de los mundos de lenguaje, de su autonomía y su autorreferencia. Es volver a conectar al lenguaje con la materialidad de la cultura viviente. El lenguaje pasa a ser parte de una unidad mayor de presenciaausencia.

\section{Referencias}

ALLOUCH, Jean. Erótica del duelo en tiempos de la muerte seca. Buenos Aires: Literales, 2006. 
BARTÍS, Ricardo. Cancha con niebla. Teatro perdido: fragmentos. Buenos Aires: Atuel, 2003.

BECKETT, Samuel. Worstward Ho. London: John Calder, 1983.

BECKETT, Samuel. Mal visto mal dicho. In Relatos. Barcelona: Tusquets, 1997, p. 225-250.

BERGUA CAVERO, Jorge. Introducción general a Sófocles. In Tragedias. Barcelona, Biblioteca Gredos, VII-XXVII, 2006.

BORGES, Jorge Luis. Obras completas I 1923-1949. Buenos Aires: Emecé, 2007. Incluye “La poesía gauchesca" (del libro Discusión), p. 207-230.

BOURRIAUD, Nicolas. Radicante, Buenos Aires: Adriana Hidalgo Editora, 2009.

CARLSON, Marvin. The Haunted Stage. The Theatre as Memory Machine. Ann Arbor: The University of Michigan Press, 2003.

CARRERA, Arturo. Noche y Día. Buenos Aires: Losada, 2005.

DIÉGUEZ, Ileana. Cuerpos sin duelo. Córdoba: Documenta/Escénica, 2013.

DUBATTI, Jorge. La representación de los desaparecidos en el teatro de la postdictadura.

Comunicação apresentada no Segundo Congreso de Salud Mental y Derechos Humanos. Universidad Popular Madres de Plaza de Mayo, novembro de 2003.

DUBATTI, Jorge. ¿Estás ahí?/Ets aquí?: Javier Daulte en Buenos Aires y en Barcelona. Assaig de Teatre, Revista de l'Associació d'Investigació i Experimentació Teatral (Barcelona, España), n. 46 (juny), 2005, p. 79-83. También en J. Dubatti, El teatro sabe. La relación escena/conocimiento en once ensayos de Teatro Comparado, Buenos Aires, Atuel, 2005, p. 179-198.

DUBATTI, Jorge. Teatro y producción de sentido político en la postdictadura. Micropoéticas III. In Jorge DUBATTI (ed.). Buenos Aires: Ediciones del Centro Cultural de la Cooperación, 2006 . Incluye una introducción de J. Dubatti, "Poéticas teatrales y producción de sentido político en la postdictadura", p. 7-25.

DUBATTI, Jorge. Shakespeare en escena. Entrevista de Jorge Dubatti a Raúl Serrano. In William Shakespeare, Obras completas I: Tragedias. Eición cuidada por Pablo Ingberg, Madrid: Losada, 2006b, p. 57-65

DUBATTI, Jorge. Filosofía del Teatro I. Convivio, experiencia, subjetividad. Buenos Aires: Atuel, 2007a.

DUBATTI, Jorge. De cómo cambiar el signo de lo real. In Rodolfo Braceli, Vincent, te espero desnuda al final del libro (Poemanovela, casiteatro). Córdoba: Alción. Epílogo de J. Dubatti, 2007 b, p. 169-171. $2^{\circ}$ edición. Buenos Aires: Galerna, 2008. Posfacio (para la segunda edición) de J. Dubatti, p. 155-157.

DUBATTI, Jorge. Por qué hablamos de Postdictadura 1983-2008. La Revista del CCC [en línea]. Septiembre / Diciembre, n. 4, 2008a. Disponível em: http:/ / www.centrocultural.coop/revista/ articulo/85/. Acesso 27/01/2009.

DUBATTI, Jorge. Antonin Artaud, el actor hierofánico y el primer Teatro de la Crueldad. In Historia del actor. De la escena clásica al presente, J. Dubatti (coor.). Buenos Aires: Colihue Teatro, 2008b, p. 215-232. También en Revista Colombiana de las Artes Escénicas, Universidad de Caldas (Colombia), 
vol. II, n. 1, enero-junio 2008, 70-83.

DUBATTI, Jorge. Filosofía del Teatro II. Cuerpo poético y función ontológica. Buenos Aires: Atuel, 2010.

DUBATTI, Jorge. Los muertos que regresan. Artez. Revista de las Artes Escénicas. Bilbao, n. 175 (noviembre 2011), 2011a, p. 70-71. Sobre Hamlet, dirección de Thomas Ostermeier, y El cordero de ojos azules de Gonzalo Demaría.

DUBATTI, Jorge. El teatro de los muertos. Ñ Revista de Cultura, n. 420, 15 de octubre de 2011, Columna Opinión, 2011b, p. 35.

DUBATTI, Jorge. Introducción a los estudios teatrales. Propedéutica. Buenos Aires: Atuel, 2012a. (Hay edición mexicana: Introducción a los estudios teatrales. Diez puntos de partida. México: Libros de Godot, 2011).

DUBATTI, Jorge. Cien años de teatro argentino. Desde 1910 a nuestros días. Buenos Aires: BiblosFundación OSDE, 2012b.

DUBATTI, Jorge. Los hechizados, versión libre de Lástima que sea una puta de John Ford. Tragedia y teatro de los muertos. Tiempo Argentino, Suplemento Cultura, domingo 8 de diciembre, 2013a, p. 7.

DUBATTI, Jorge. Teatro Comparado, reescrituras, política de la diferencia: potenciar la percepción del presente. La revista del CCC [en línea]. Septiembre / Diciembre, n. 19, 2013b. Disponível em: http://www.centrocultural.coop/revista/articulo/447/. Acesso em 09/12/2013.

DUBATTI, Jorge. Teatro, comunicación, estimulación, afectación: reflexiones sobre la "zona" teatral. Actas II Congreso Latinoamericano de Arte, Educación y Análisis del Discurso. Universidad Nacional de San Luis, Facultad de Ciencias Humanas, Secretaría de Políticas Universitarias, San Luis, 2013c. (no prelo)

DUBATTI, Jorge. Filosofía del Teatro y espacio teatral: convivio, cuerpos poéticos, zona de experiencia. Actas 5tas Jornadas de Investigación Teatral “El teatro y el espacio escénico". Universidad Nacional de Tucumán, Facultad de Artes y Facultad de Arquitectura y Urbanismo, Departamento de Teatro, Instituto de Investigaciones Estéticas, Proyecto Relevo Histórico Integral de la Actividad Teatral de Tucumán (1859-2007), San Miguel de Tucumán, 2013d. (no prelo)

DUBATTI, Jorge. Filosofía del Teatro III. 2014(Atuel, no prelo).

FREUD, Sigmund. Duelo y melancolía. Obras completas XI. Buenos Aires: Amorrortu, 1979

GARCÍA GUAl, Carlos. Enigmático Edipo. Mito y tragedia. Madrid: FCE, 2012.

GARCÍA LORCA, Federico. Obra completa. Ed. Miguel García-Posada, sete tomos. Madrid: Akal, 2008.

HARSHAW, Benjamin. Fictionality and Fields of Reference. Remarks on a Theoretical Framework. Poetics Today, n. 5, vol. 2, 1984, p. 227-251.

LEHMANN, Hans-Thies. Teatro posdramático. México-Murcia: Paso de Gato/CENDEAC, 2013.

LÓPEZ FACAL, Javier. Introducción a Fábulas de Babrio. In Esopo y Babrio, Fábulas, Vida / Fábulas. 
Barcelona: Biblioteca Gredos, 2006, p. 285-302.

LÓPEZ OCÓN, Mónica. Teléfono. Tiempo Argentino, Suplemento Cultura, Sección “La Columna Torcida", domingo 12 de janeiro, 2014, p. 8.

MARGARIT, Lucas. Leer a Shakespeare. Notas sobre la ambigüedad. Buenos Aires: Quadrata/ Biblioteca Nacional, 2013.

MUSITANO, Adriana.

2011 Poéticas de lo cadavérico. Teatro, plástica y videoarte de fines del siglo XX, Córdoba (Argentina), Editorial Comunicarte.

PAVLOVSKY, Eduardo. Teatro completo VII, estudio preliminar (p. 5-31), notas y edición al cuidado de J. Dubatti. Buenos Aires: Editorial Atuel, Col. Atuel/Teatro, 2010.

ROZIK, Eli. The Roots of Theatre. Rethinking ritual and other theories of origin, Iowa, University of Iowa Press, 2002. (Hay traducción al castellano: Las raíces del teatro. Repensando el ritual y otras teorías sobre el origen, traducción de Nora Lía Sormani y Ricardo Dubatti, Buenos Aires, Colihue Teatro, 2014.)

SÁNCHEZ SANTARELLI, Santiago. El teatro asume la muerte de la Argentina, y de alguna manera la exorciza. Entrevista a Jorge Dubatti. Ciento Cincuenta Monos, n. 5 (setembro), 2009, p. 28-41. Disponível em www.150monos.blogspot.com

SHAKESPEARE, William. The Complete Works London: Oxford University Press, 1991.

VACAREZZA, Alberto. Vacarezza inédito. La noche del forastero y Don Juan el almacenero. Edición al cuidado de Jorge Dubatti. Bahía Blanca: Universidad Nacional del Sur/ EDIUNS, 2014.

VEZZETTI, Hugo. Pasado y presente. Guerra, dictadura y sociedad en la Argentina. Buenos Aires: Siglo Veintiuno Editores Argentina, 2002. 